\title{
Open rhinoplasty for correction of the secondary nasal deformity due to the Marcks triangular flap cleft lip repair
}

\author{
Geoffrey G Hallock MD \\ Division of Plastic Surgery, The Lehigh Valley Hospital, Allentown, Pennsylvania, USA
}

GG Hallock. Open rhinoplasty for correction of the secondary nasal deformity due to the Marcks triangular flap cleft lip repair. Can J Plast Surg 1999;7(2):75-79.

The Marcks Z-plasty modification of the Tennison triangular flap cleft lip repair results in excellent preservation of the Cupid's bow, but in more severe clefts this technique is stigmatized by a characteristic V-shaped nasal rim deformity. This has proven extremely difficult to correct secondarily. An open rhinoplasty technique is advocated because superior exposure is essential to visualize deficient components, as well as the malformed lower lateral cartilage, which is a direct result of this lip repair. Nevertheless, typical results remain substandard in terms of achieving nasal symmetry as opposed to routine use of the Millard rotation-advancement repair, with or without primary nasal correction.

Key Words: Cleft lip nasal deformity; Marcks cleft lip repair; Open rhinoplasty

Rhinoplastie ouverte pour la correction d'une difformité nasale secondaire attribuable à la réparation d'un bec de lièvre par lambeau triangulaire de Marcks

\footnotetext{
RÉSUMÉ : La modification en $\mathrm{Z}$ de Marcks de la réparation du bec de lièvre au moyen du lambeau triangulaire de Tennison donne une préservation excellente de l'arc de Cupidon, mais dans les cas plus graves, cette technique donne lieu à une difformité du rebord nasal en V, caractéristique. Ce problème s'est révélé extrêmement difficile à corriger par le suite. Une technique de rhinoplastie ouverte est proposée en raison d'une meilleure exposition qui est essentielle pour visualiser les composantes déficientes, de même que le cartilage latéral inférieur déformé, conséquence directe de la réparation labiale. Néanmoins, les résultats typiques demeurent sous la norme en termes de symétrie du nez par opposition à l'emploi de routine d'une réparation par avancée et rotation de Millard, avec ou sans correction nasale primaire.
}

\begin{abstract}
A lmost half a century ago, Tennison (1) proposed a triangular flap cleft lip repair that for the first time preserved the existing lip elements and permitted the creation of a normal Cupid's bow. Brauer (2) and Randall (3) are better known for improving this original concept, but Millard (4) credits Marcks for popularizing Tennison's method while developing his own Z-plasty modification. Trevaskis et al (5) later recapitulated their design more scientifically with a mathematical solution using a $60^{\circ}$ tip angle and standardized templates to design the Z-plasty flaps. This reflected similar independent observations by Davies (6) as revised by Lewis (7), and Jayapathy et al (8).
\end{abstract}

Correspondence: Dr GG Hallock, 1230 South Cedar Crest Boulevard, Suite 306, Allentown, Pennsylvania 18103, USA. Telephone

610-435-7555, fax 610-770-6390
The Marcks and Trevaskis Z-plasty version of the triangular flap cleft lip repair, when correctly performed, results in an exquisite appearance of the lip. Their legacy remains extensive throughout eastern Pennsylvania, with disciples of this technique spread throughout North America, where this method of lip repair often can be instantly discerned due to the characteristic nasal appearance that develops following correction of the more severe unilateral cleft lip. Not unlike other secondary cleft lip nasal deformities, several deficiencies exist, including that of the alar cartilage that is typically malpositioned posteriorly, laterally and inferiorly $(9,10)$, but peculiar to this repair is buckling of the alar rim in a $\mathrm{V}$-pattern due to the requisite medial transposition of the superior cleft side Z-plasty flap. Tennison (1) advocated correction of any nasal deformity at the primary operation but never entirely accomplished this. Marcks et al (11) recognized the "typical droop of the lower lateral cartilage" after his modified repair 

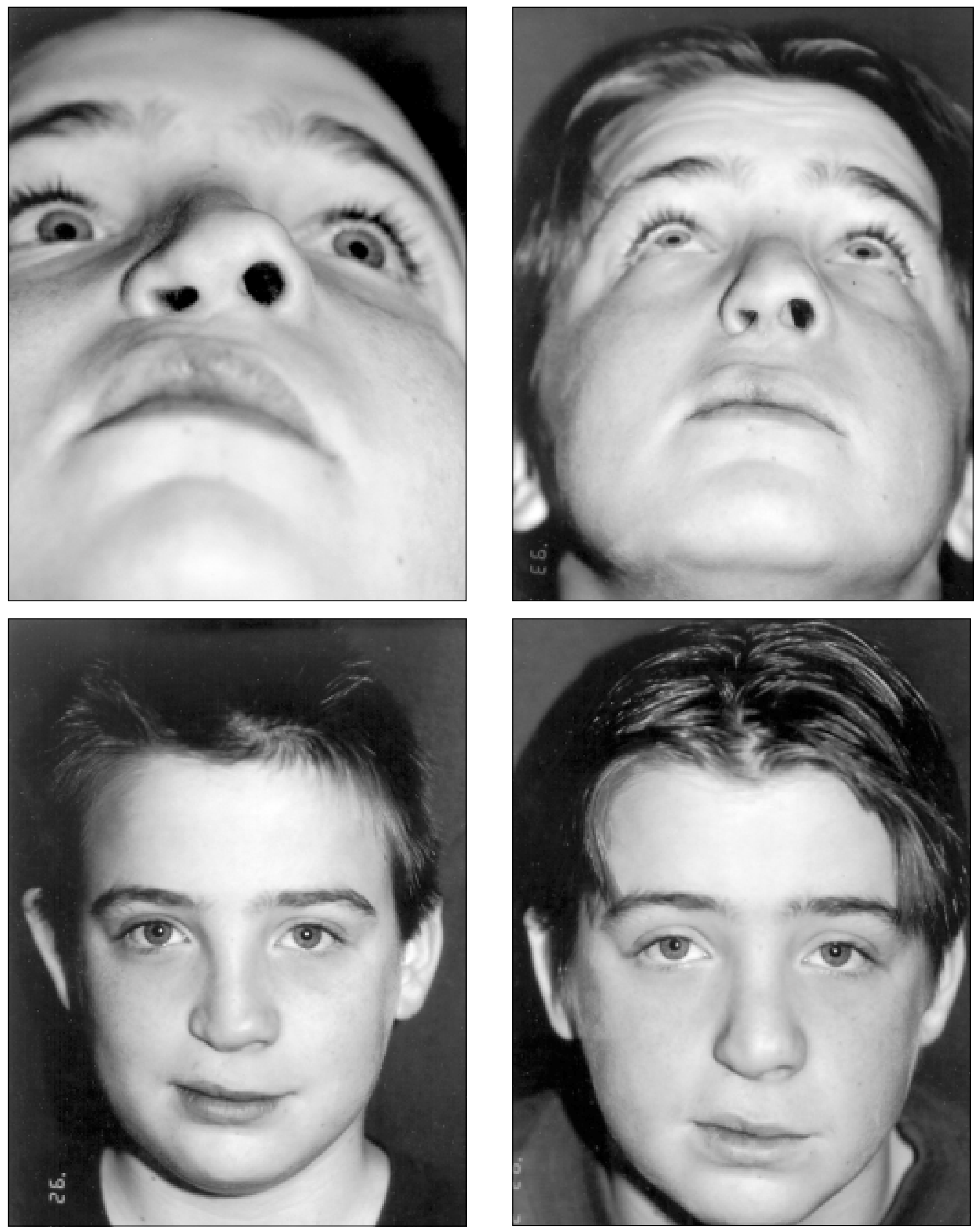

Figure 1) Top left Submental vertex view of a Marcks Z-plasty repair of a right unilateral cleft lip, with the typical buckled right alar rim, slumped nasal dome, foreshortened columella on the cleft side and horizontally flared nostril. Bottom left Frontal view demonstrating the superior displacement of the right alar base and hidden right nostril. Top right Definite improvement with elevation of right alar dome, but height is still deficient with residual narrowing of the right nares now with a vertical orientation. Bottom right Improvement confirmed on anteroposterior projection 


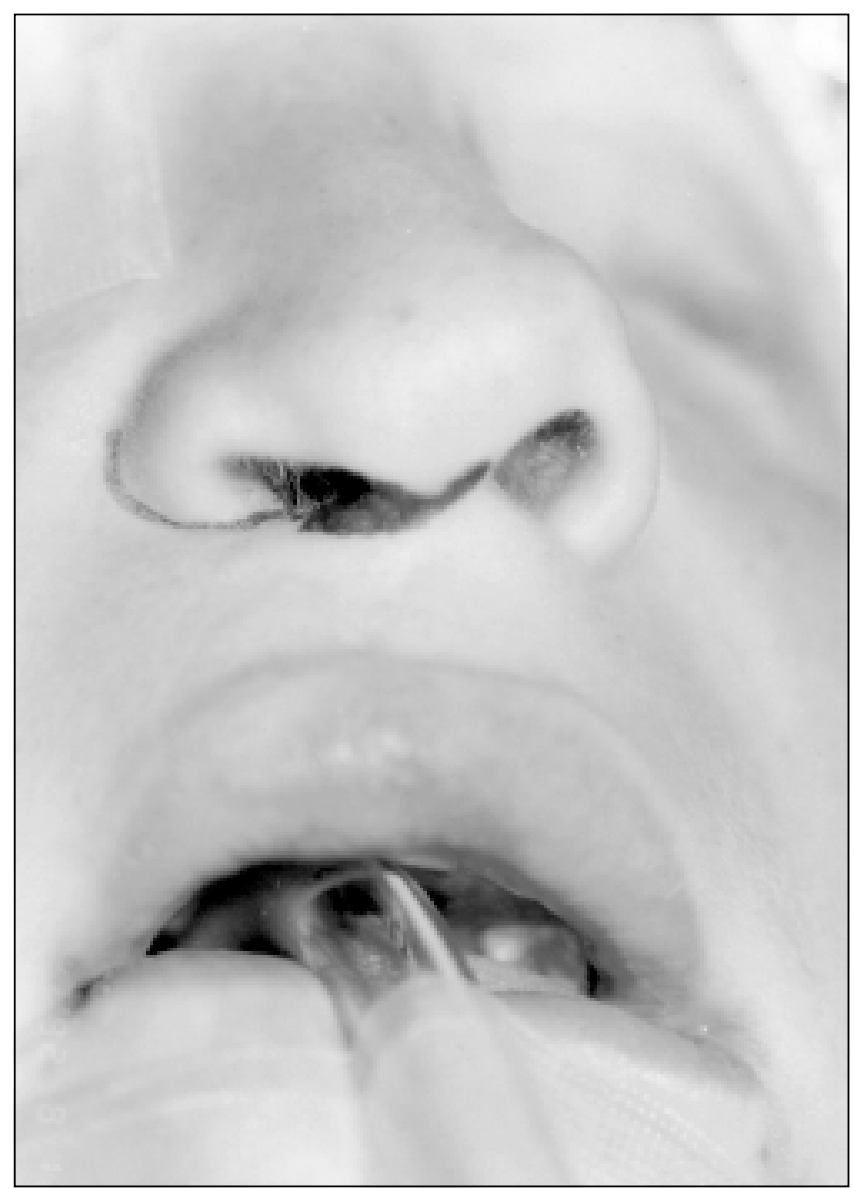

Figure 1) Top left Technique for open rhinoplasty with mid-columella $V$-incision marked, nostril floor accentuated where portion will be advanced in $V-Y$ fashion into the columella, as well as the right alar base for later repositioning inferiorly and medially. Top right Nasal skin retracted showing exposure of both lower lateral cartilages, with buckling and deficiency noted in the cleft-side lateral crus corresponding to the alar deformity grossly observed (cartilage was elevated independent of any lining). Bottom right The medial crura were sewn together after medial advancement of cleft-side lateral crus and an onlay auricular graft placed to complete the correction

but opted for a secondary nasal correction using intranasal incisions, as was common at the time. Many of these patients still desire improvement of their unique nasal deformity, which can be challenging even with direct visualization of the pertinent anatomy as afforded by an open rhinoplasty technique.

\section{PATIENTS AND METHODS}

Over the past 16 years, many individuals at the Allentown Cleft Lip and Palate Clinic, Allentown, Pennsylvania, that had been personally treated by Marcks or Trevaskis using their Z-plasty triangular flap modification for unilateral cleft lip repair have been evaluated $(5,11,12)$. Most of these patients have required only minor lip scar or nasal revisions, but over this time period four adolescents specifically requested elimination of the characteristic cleft-side alar rim buckling. In all cases, this was achieved using an open rhinoplasty approach patterned after Rethi described by Cronin and Denkler (10).
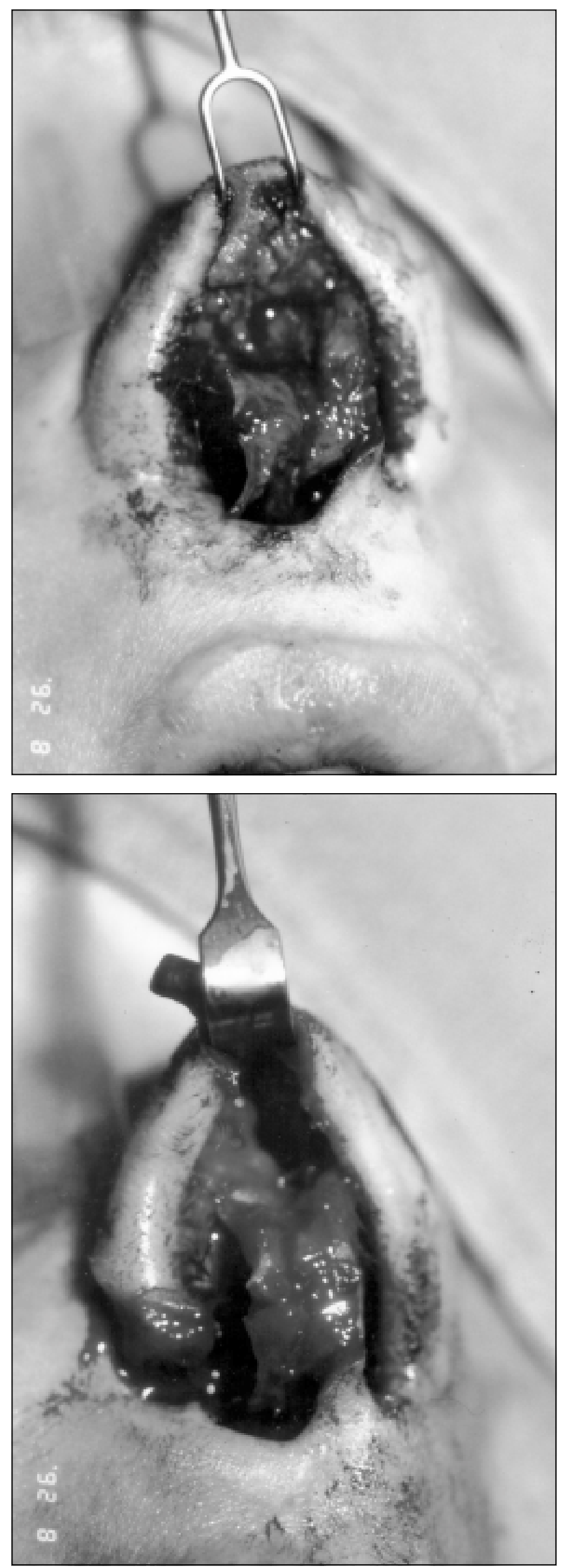

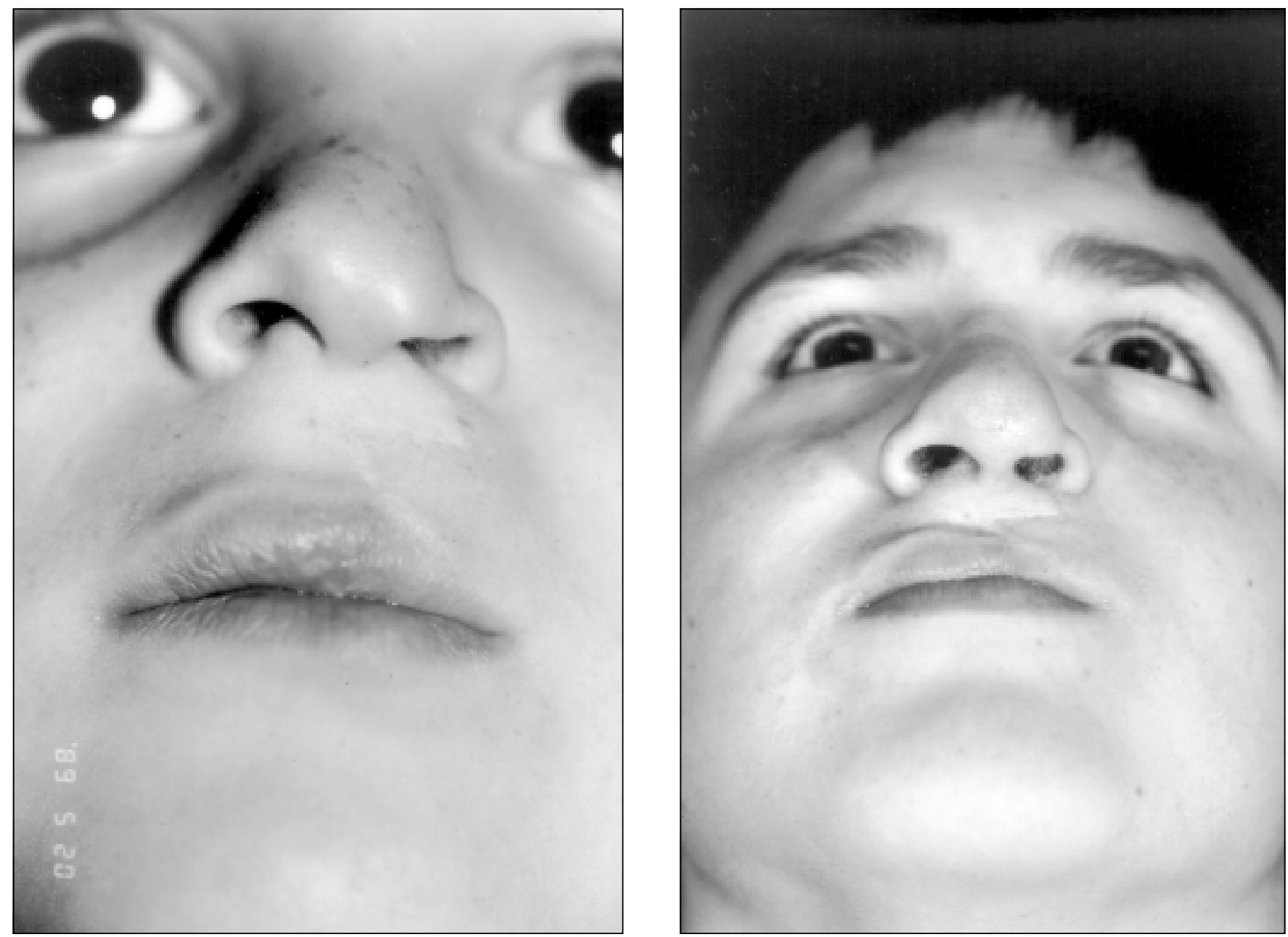

Figure 2) Left Left unilateral cleft lip repair with conspicuous Z-plasty scar crossing the philtrum, characteristic V-shaped nasal rim on the cleft-side, and superior and lateral displacement of the left alar base. Right Considerable improvement after open rhinoplasty and onlay alar cartilage graft, but still obvious asymmetry; note that the columella scar used for the open rhinoplasty is not visible only seven months after secondary correction

An existing columellar scar can be used (13), but a transcolumellar V-shaped incision through the narrowest portion permits subsequent closure in a V-Y fashion to provide some columellar lengthening, which is invariably shortened on the cleft side (10). The ends of this V-shaped incision are extended vertically just inside the vestibule, continuing as alar rim or marginal incisions along the caudal end of the lower lateral cartilage. The mucosa can be left on the undersurface of the cartilage to improve its vascularity and support, especially if scoring for recontouring is necessary, but a parallel intercartilaginous incision is required to allow medial cartilage displacement (10). By blunt dissection, the nasal tip can be retracted up to the nasion for eventual exposure of both upper lateral cartilages and the nasal bones, if desired (14).

Usually, the laterally slumped cleft-side lateral crus must be raised and shifted medially to create an appropriate nasal dome with the two medial crura sutured together after removal of any intervening tissues to define the tip. Permanent sutures to both upper lateral cartilages and/or the septum support this advancement. This recontouring and sculpting, with or without cartilage grafts, must result in symmetry with the non-cleft side as seen directly by this open approach (10). The nasal skin must be constantly redraped to observe the correctness of this reconfiguration. At the time of closure, excessive alar webbing, commonly due to the observed buckling, can be trimmed, and the alar base shifted as needed to match the contralateral side. Splints or external sutures do not need to be routinely employed.

\section{RESULTS}

In the four adolescents who had secondary correction of their residual nasal deformity following a Marcks/Trevaskis triangular flap repair of a unilateral cleft lip, the cleft-side lateral crus of the lower lateral cartilage was always difficult to dissect free from the overlying skin and would have been impossible without an open rhinoplasty for direct visualization (Figure 1). Cartilage onlay grafts were used in two patients to augment the cleft-side alar cartilage, and in one patient the non-cleft side as well. The patient who did not have a cartilage graft remained deficient in prominence of the cleft-side nasal dome, but declined reoperation. Some worthwhile improvement was achieved in all patients, but perfect confor- 
mity of the lower lateral cartilage to match its mate was never possible (Figure 2), emphasizing the difficulty of secondary correction for this peculiar nasal deformity, even using an open approach.

\section{DISCUSSION}

Marcks et al (11) recognized the subsequent nasal deformity as the major liability of the triangular flap modification when repairing the severe unilateral cleft lip. Secondary corrections frequently proved inadequate due to the interim continued growth of malformed, tethered and malpositioned structures that exacerbated the original problem (9). Unfortunately, the buckling of the alar rim characteristic of this technique of cleft lip repair becomes more difficult to straighten as the alar cartilage loses its intrinsic pliability with age (15). Also, despite the potential use of local mucosal flaps, the vestibular lining shrinks and is difficult to replace, which is essential to prevent recidivism after recontouring of the alar rim $(10,13)$.

These problems were not seen in the rest of our clinic population, where the Millard rotation-advancement repair has become the standard technique for the unilateral cleft lip, although primary nasal repair at the time of the definitive lip closure is now also routine, which in itself may be the reason that any significant long term cleft lip nasal deformities are no longer observed (9,15-18). Many long term studies have shown that such primary repair does not cause growth retardation, provides permanent correction and eliminates any psychosocial embarrassment while awaiting secondary surgery (19). These facts had not yet been accepted by contemporaries of Marcks, but Broadbent and Woolf (19) have recently shown that primary nasal correction is possible at the time of their version of triangular flap lip repair; this provides a superior result that can avoid secondary correction, which may also be applicable to the Marcks modification.

Because the past cannot be rewritten, any current patients who were treated using the Marcks/Trevaskis modification of Tennison's triangular flap cleft lip repair, if desirous of improving their nasal deformity, may be best served by an open rhinoplasty technique, because closed methods have generally proved to be insufficient (20). This allows identification of often obscure or deficient structures by direct visualization. Once these key anatomical components are isolated, accurate repositioning with secure stabilization by permanent sutures plus precise onlay cartilage grafts can be achieved as demanded to provide symmetry. Accessory procedures such as caudal septoplasty, alar base adjustment and columellar lengthening are readily accomplished. The cost of these advantages is a columellar scar and extra dissection confined to the central portion of the columella (14). Uncorrectable nasal deformities, in spite of improvements using this open rhinoplasty approach, remain far more conspicuous than any such scar. These ultimate imperfections support the contention that primary nasal correction at the time of cleft lip closure may result in a better long term outcome $(9,15-19)$.

\section{CONCLUSIONS}

The Marcks modification of the Tennison triangular flap unilateral cleft lip repair results in a characteristic nasal deformity. An open rhinoplasty approach affords the best method to not only visualize inherent deficiencies, but also correct long-standing malformed and malpositioned nasal components that resulted from this repair. Even with an open rhinoplasty approach, secondary correction of this cleft lip nasal deformity has residual imperfections. These observations suggest that by using primary nasal repair at the time of definitive lip closure these nasal stigmata may be avoided, regardless of what type of lip repair is performed.

\section{REFERENCES}

1. Tennison CW. The repair of the unilateral cleft lip by the stencil method. Plast Reconstr Surg 1952;9:115-20.

2. Brauer RO. Repair of unilateral cleft lip: triangular flap repairs. Clin Plast Surg 1985;12:595-604.

3. Randall P. A triangular flap operation for the primary repair of unilateral clefts of the lip. Plast Reconstr Surg 1959;23:331-47.

4. Millard DR Jr. Preservation of the Cupid's bow. Cleft Craft: The Evolution of its Surgery, Volume 1: The Unilateral Deformity. Boston: Little, Brown \& Company, 1976:139-43.

5. Trevaskis AE, Lee YH, Cochran WG. Unilateral cleft lip repair. Ann Plast Surg 1979;3:516-22.

6. Davies D. The repair of the unilateral cleft lip. Br J Plast Surg 1965;18:254-9.

7. Lewis MB. Unilateral cleft lip repair: Z-plasty. Clin Plast Surg 1993;20:647-57.

8. Jayapathy B, Huffman WC, Lierle DM. The Z-plastic procedure: Some mathematic considerations and application to cleft lip. Plast Reconstr Surg 1960;26:203-8.

9. Armstrong GT, Burk RW III, Griffin DW, Howard PS. A modification of the primary nasal correction in the rotation-advancement unilateral cleft lip repair. Ann Plast Surg 1997;38:236-45.

10. Cronin TD, Denkler KA. Correction of the unilateral cleft lip nose. Plast Reconstr Surg 1988;82:419-32.

11. Marcks KM, Trevaskis AE, Berg EM, Puchner G. Nasal defects associated with cleft lip deformity. Plast Reconstr Surg 1964;34:176-81.

12. Marcks KM, Trevaskis AE, DaCosta A. Further observation in cleft lip repair. Plast Reconstr Surg 1953;12:392-402.

13. Harashina T. Open reverse- $U$ incision technique for secondary correction of unilateral cleft lip nose deformity. Br J Plast Surg 1990;43:557-64.

14. Gruber RP. Open rhinoplasty. Clin Plast Surg 1988;15:95-114.

15. McComb H. Primary correction of unilateral cleft lip nasal deformity: a 10-year review. Plast Reconstr Surg 1985;75:791-9.

16. Noordhoff MS, Chen YR, Chen KT, Hong KF, Lo LJ. The surgical technique for the complete unilateral cleft lip-nasal deformity. Oper Tech Plast Reconstr Surg 1995;2:167-74.

17. Trott JA, Mohan N. A preliminary report on open tip rhinoplasty at the time of lip repair in unilateral cleft lip and palate: the Alor Setar experience. Br J Plast Surg 1993;46:363-70.

18. Salyer KE. Primary correction of the unilateral cleft lip nose: a 15-year experience. Plast Reconstr Surg 1986;77:558-68.

19. Broadbent TR, Woolf RM. Cleft lip nasal deformity. Ann Plast Surg 1984;12:216-34.

20. Coghlan BA, Boorman JG. Objective evaluation of the Tajima secondary cleft lip nose correction. Br J Plast Surg 1996;49:457-61. 